ORIGINAL ARTICLE

\title{
Knowledge about and Attitude towards Epilepsy among Menit Community, Southwest Ethiopia
}

\author{
Andualem Henok $^{1 *}$, Tafesse Lamaro ${ }^{2}$
}

OPEN ACCESS

Citation: Andualem Henok, Tafesse

Lamaro. Knowledge about and Attitude

towards Epilepsy among Menit

Community, Southwest Ethiopia. Ethiop

J Health Sci 2017;27(1):47-58. doi:

http://dx.doi.org/10.4314/ejhs.v27i1.7

Received: July 27, 2016

Accepted: October 9, 2016

Published: January 1, 2017

Copyright: Andualem H, et al. This is an

open access article distributed under the

terms of the Creative Commons

Attribution License, which permits

unrestricted use, distribution, and

reproduction in any medium, provided the original author and source are credited.

Funding: Mizan-Tepi University

Competing Interests: The authors

declare that this manuscript was approved

by all authors in its form and that no

competing interest exists.

Affiliation and Correspondence:

${ }^{1}$ Department of Public Health, Mizan-

Tepi University, Mizan, Ethiopia

${ }^{2}$ Department of Nursing, Mizan-Tepi

University, Mizan, Ethiopia

"Email: andualemhenok@gmail.com

\section{ABSTRACT}

BACKGROUND: Nearly $80 \%$ of the people with epilepsy are found in developing countries, where epilepsy remains a major public health problem, not only because of its health implications but also for its social, cultural, psychological and economic effects. The objective of this study was to assess knowledge and attitude of Menit community in Benchi-Maji Zone as regards epilepsy. METHODS: The study was conducted in Menit Goldia Province, one of the provinces of Bench-Maji Zone. Community based descriptive cross-sectional study was employed. Households were selected by using systematic sampling technique. Data was collected through pretested interviewer administered questionnaire. Data was cleaned, coded and entered in to EPI data version 3.1. The data was cleaned and transported into SPSS for analysis.

RESULTS: Among the study participants, 808(97.1\%) ever heard about epilepsy, $85.3 \%$ reported that epilepsy is a mental disease where as $40.6 \%, 49 \%$ and $49.4 \%$ respectively believed that it is hereditary, contagious, and God's curse. Among the respondents, 252(30\%) think that epileptics should be isolated from the community, 387(46.1\%) and 336(40\%) do not want to shake hands with epileptics and keep their children away from epileptic patients respectively. In this study, $85.6 \%$ and $86.8 \%$ of the respondents were not knowledgeable about and had negative attitude towards epilepsy respectively. Ethnicity and educational status were significantly associated with knowledge and attitude. The FGD participants noted that the disease is God's curse, and they lacked knowledge about the cause of epilepsy.

CONCLUSION: The study participants' level of knowledge about and attitude towards epilepsy was not satisfactory. Thus, it needs attention from concerned bodies.

KEYWORDS: Epilepsy, Knowledge, Attitude, Ethiopia

\section{INTRODUCTION}

Epilepsy is one of the world's most common chronic neurological disorders. It is characterized by recurrent derangement of the nervous system due to sudden excessive disorderly discharge of the cerebral neurons that result in almost instantaneous disturbance of sensation and loss of consciousness. It is becoming a burden for more than 70 million people in the world (1). Nearly $80 \%$ of the people with 
epilepsy are found in developing countries, where the disease remains a major public health problem, not only because of its health implications but also for its social, cultural, psychological and economic effects (2-4).

Epilepsy contributed more than 7 million to the global burden of diseases in 2000 measured in disability adjusted life years (DALYs) $(5,6)$. It is apparent that close to $90 \%$ of the worldwide burden of epilepsy is found in developing regions, with more than half occurring in the $39 \%$ of the global population living in countries with the highest levels of premature mortality, the lowest levels of premature mortality and the least levels of income $(6,7)$.

The reported prevalence of active epilepsy in developing countries ranges from 5 to 10 per 1,000 people, and it is more prevalent in rural communities $(8,9)$. Universally and all over the history, epilepsy has been culturally an undervalued condition (10).

Fear, misunderstanding, lack of awareness, wrong beliefs and the resulting social stigma and discrimination compounding epilepsy make epileptic patients live poor quality life (11). Epileptic patients and their families have suffered ostracism by society and deprivation of treatment, leading to frequent injuries and death (12).

Epilepsy is a fascinating topic by nature and is poorly understood by the public, even among people who know someone with the disorder. Lack of knowledge about the causes of epilepsy has been associated with negative attitudes, beliefs, and stigma $(4,8,13)$. Lack of understanding about epilepsy is a leading cause of discrimination in the workplace and in schools (14). Gauging the knowledge, attitude and understanding of epilepsy is the first measure towards alleviating stigma and discrimination (1). Most studies showed that a high number of people ever heard about epilepsy. However, most of them had lower level of knowledge (15-18). A significant number of people argued that epilepsy is mental disease, hereditary disease, contagious, evil spirit or God's curse (15-23). Due to negative attitude towards epilepsy, many people do not want to work or live with epileptics. Large numbers of people do not want even to shake hands with epileptic individuals, and they try to keep their children away from these patients (17). Due to this negative attitude, epileptic patients may not get job opportunities because many people do not want to hire them. Despite these evidences, there is no study conducted to assess knowledge and attitude towards epilepsy in Menit Community. Therefore, this study was designed to assess knowledge and attitude of Menit Community in Benchi-Maji Zone as regards epilepsy.

\section{METHODS}

Study area and period: The study was conducted in Menit Goldia Province, Bench-Maji Zone, from May to June 2015. This site is found in south western Ethiopia which is 620 kilometers far from Addis Ababa.

Study Design: Community based cross-sectional design was employed in the study. It was supplemented with qualitative data collected through Focused Group Discussion (FGD).

Source and study population: The source population was all people of Menit Goldia District while the study population was all people aged 18 years or above selected from eight kebeles. Households in selected kebeles were sampling units whereas selected individuals in each household were study units.

\section{Inclusion and exclusion criteria}

Inclusion criteria: Individuals who were 18 years or above and those who lived for more than six months in Menit Goldia Province were included. For the qualitative study, individuals who can best explain their condition were included in the study.

Exclusion criteria: Severely ill and nonpermanent residents were excluded from the study. For the qualitative study, individuals who were participated in the quantitative component of study were excluded.

Sample size determination: The sample size was determined by using single population proportion formula. This yielded 384 samples, and by considering $10 \%$ non-response rate and design effect of 2, the final sample size was 846 individuals. For the qualitative, six FGDs were conducted by considering the data saturation.

Sampling technique: The majority of Menit Community dwelled in two provinces namely; Menit Goldia and Menit Shasha. Of the two,

DOI: http://dx.doi.org/10.4314/ejhs.v27i1.7 
Menit Goldia Province was selected purposively because there were many epileptic cases in this province. The province has a total of 31 kebeles (sub-localities), and of these, the eight kebeles were selected by using lottery method. Households were selected by using systematic sampling technique after house numbering was conducted. Inhabitants who were readily available and consented to the request of the researcher were interviewed. For the qualitative part, three FGDs from male and three FGDs from female participants who were not involved in the quantitative study were selected. Purposively, community leaders, religious leaders and other community members who better knew the community were selected.

Data collection methods and procedures: Data was collected by using pretested interviewer administered questionnaire. It was translated into local languages and backtranslated into English by language experts to ensure consistency. The questionnaire was pretested among community members who were not study participants. It was then amended based on the result of the pretest. The questionnaire was designed to cover sociodemographic characteristics, knowledge and attitude questions regarding epilepsy. Data collection was conducted by eight Health Extension Workers (HEWs). The supervisors were two BSc (Bachelor of Science) nurses. The supervisors and data collectors were trained for two days on data collection. For the qualitative part, FGD guide was developed by the principal investigators and translated into a local language (Menitegna) by experts. The FGD was moderated by two BSc nurses (one male and one female) who were fluent in local languages and trained on FGD. The FGD was tape-recorded, and notes were taken by a HEW. The FGD took 50 to 60 minutes. Separate and silent rooms were used to conduct FGD.

Operational definitions: Knowledge about epilepsy was assessed based on 10 knowledge questions. Individuals who scored above the mean were considered as knowledgeable while those who scored below the mean were considered as not knowledgeable. Attitude towards epilepsy was assessed based on 12 attitude questions. Participants who scored above the mean were considered as having positive attitude and those who scored less than the mean were considered as having negative attitude.

Data analysis procedure: Quantitative data was checked for completeness, coded and entered into EPI data version 3.1. After complete entry, data was transported to SPSS (Statistical Package for Social Sciences) statistical package for analysis. Analysis was done to calculate frequencies and proportions. Binary logistic regression was used to assess factors associated with knowledge and attitude regarding epilepsy. Variables with P-value less than 0.2 in bivariate analysis and other important variables were taken to multivariate analysis. The results were presented using appropriate frequencies, proportions and 95\% confidence interval. P-value less than 0.05 was considered significant. The data from the FGD was transcribed manually and translated into English. Finally, the qualitative part was analyzed narratively.

Data quality management: Data quality was assured by pretesting the questionnaire, by checking data for completeness and by supervising data collection process. The quality of qualitative data was assured by training data collectors, by tape- recording responses and by conducting FGDs in separate silent rooms.

Ethical consideration: Ethical clearance was obtained from Mizan-Tepi University Research and Ethical Committee. Permission was asked from the province administration. Informed consent was obtained from study participants. Participants were informed about the objectives of the study. The names of respondents were not included from the questionnaire. Data collectors were trained on keeping confidentiality of the respondents.

\section{RESULTS}

Sociodemographic characteristics of study participants: In this study, 840 individuals completed the interviewer administered questionnaire (response rate was 99.3\%). The majority of the respondents were in the age range of 21- 30 years (52.2\%). Regarding the distance of respondents' houses from the nearest health institution, more than half $(52.3 \%)$ reported that it 
Vol. 27, No. 1

January 2017

took less than 10 kilometers. The majority of the study participants were of Menit ethnic affiliation (67.7\%). More than two-third (68.3\%) did not read and write. In nearly two-thirds of the participants, income was reported to be less than 25 dollars a month. More than two-thirds were married. Nearly half were farmers (Table 1).

Table 1: Sociodemographic characteristics of study participants, Menit, 2015.

\begin{tabular}{|c|c|c|}
\hline Variables & Frequency & Percentage \\
\hline \multicolumn{3}{|c|}{ Age group(years) $(n=840)$} \\
\hline$<20$ & 76 & 9.1 \\
\hline $21-25$ & 221 & 26.5 \\
\hline $26-30$ & 214 & 25.7 \\
\hline $31-35$ & 154 & 18.5 \\
\hline$>36$ & 169 & 20.3 \\
\hline \multicolumn{3}{|l|}{$\operatorname{Sex}(n=840)$} \\
\hline Male & 400 & 47.6 \\
\hline Female & 440 & 52.4 \\
\hline \multicolumn{3}{|c|}{ Income in dollars $(n=828)$} \\
\hline$<25$ & 527 & 63.6 \\
\hline $25-50$ & 211 & 25.5 \\
\hline$>50$ & 90 & 10.9 \\
\hline \multicolumn{3}{|c|}{ Distance from home to health facility } \\
\hline$<10$ & 316 & 37.8 \\
\hline $11-20$ & 62 & 7.4 \\
\hline $21-40$ & 21 & 2.5 \\
\hline$>40$ & & \\
\hline \multicolumn{3}{|l|}{ Religion $(\mathrm{n}=840)$} \\
\hline Orthodox & 313 & 37.3 \\
\hline Muslim & 45 & 5.4 \\
\hline Protestant & 461 & 54.9 \\
\hline Catholic & 6 & 0.7 \\
\hline Others & 15 & 1.8 \\
\hline \multicolumn{3}{|l|}{ Marital status $(n=840)$} \\
\hline Married & 598 & 71.2 \\
\hline Single & 189 & 22.5 \\
\hline Widow & 28 & 3.3 \\
\hline Divorced & 20 & 2.4 \\
\hline Others & 5 & 0.6 \\
\hline \multicolumn{3}{|l|}{ Ethnicity $(n=837)$} \\
\hline Bench & 159 & 19 \\
\hline Menit & 567 & 67.7 \\
\hline Kaffa & 6 & 0.7 \\
\hline Amhara & 84 & 10 \\
\hline Others & 21 & 2.5 \\
\hline
\end{tabular}

DOI: http://dx.doi.org/10.4314/ejhs.v27i1.7 
Educational status $(\mathrm{n}=840)$

Do not read and write

547

128

Read and write only

$1-4$

$5-8$

0thers
59

40

39

441

177

126

87
68.3

15.2

7

4.8

4.6

53.1

21.3

15.2

10.5

Knowledge of study participants about to Epilepsy: Among the study participants, 808(97.1\%) ever heard about epilepsy. The mmajority $(85.3 \%)$ reported that epilepsy is a mental disease whereas $40.6 \%, 49 \%$ and $49.4 \%$ believed that it is transgenerational (hereditary),

contagious and God's curse respectively (Table 2). In this study, only $14.4 \%$ of the participants were knowledgeable. The qqualitative study revealed that the participants' knowledge on the cause and treatment of epilepsy was not adequate.

Table 2 Knowledge of study participants regarding epilepsy, Menit, 2015.

\begin{tabular}{lll}
\hline Variables & Frequency & Percentage \\
\hline Ever hear or read about epilepsy & & \\
Yes & 808 & 97.1 \\
No & 24 & 2.9 \\
Do you think you have enough knowledge? & 244 & 29.9 \\
$\quad$ Yes & 572 & 70.1 \\
$\quad$ No & 32 & 3.9 \\
Source of information & 659 & 80.8 \\
$\quad$ Mass media & 89 & 10.9 \\
Health worker & 3 & 0.4 \\
Family and friend & 33 & 4.0 \\
Written materials & & \\
Others & 741 & 90.8 \\
Have you ever seen epileptic patient? & 75 & 9.2 \\
Yes & & 85.3 \\
No & 696 & 14.7 \\
Is epilepsy mental disease & 120 & \\
Yes & & 40.6 \\
No & 331 & 59.4 \\
Is it transgenerational disease? & 485 & 49 \\
$\quad$ Yes & & 51 \\
No & 400 & 49.4 \\
Is it contagious? & 416 & 50.6 \\
Yes & 403 &
\end{tabular}

DOI: http://dx.doi.org/10.4314/ejhs.v27i1.7 
The FGD participants argued on the cause of epilepsy. Most participants said that they did not know the cause of the disease, but the majority agreed that it occurs naturally. A 38 years old woman said:

'Emm, we lived together for so many years; we eat together. We did not see when it transmits! Do you know what? This disease never likes hunger and anxiety."

Another participant from the male FGD group who was 45 years old said: 'Wow, we have not seen when it transmits, but it is from nature. Now you are created by God, Yah! How could one become intentionally insane?"'

The FGD participants agreed on the disease's being a curse from God. This was expressed from a 25 years old participant from the female FGD group: 'Yeah! It is a curse from God. It is not made by human beings. We know and believe it is from God."

Table 3: Attitude towards epilepsy among study participants, Menit, 2015.

\begin{tabular}{|c|c|c|}
\hline Variables & Frequency & Percentage \\
\hline \multicolumn{3}{|c|}{ Do you have family member who is epileptic? } \\
\hline Yes & 71 & 8.5 \\
\hline No & 769 & 91.5 \\
\hline \multicolumn{3}{|c|}{ Do you agree to work with epileptics? } \\
\hline Yes & 321 & 38.2 \\
\hline No & 519 & 61.8 \\
\hline \multicolumn{3}{|c|}{ Do you agree to have close relation with epileptics? } \\
\hline Yes & 330 & 39.3 \\
\hline No & 510 & 60.7 \\
\hline \multicolumn{3}{|c|}{ Do you agree to live together with epileptics? } \\
\hline Yes & 303 & 36.1 \\
\hline No & 537 & 63.9 \\
\hline Do you think & & \\
\hline Yes & & \\
\hline \multirow[t]{2}{*}{ No } & 252 & 30 \\
\hline & 588 & 70 \\
\hline \multicolumn{3}{|c|}{ Do you think epileptics can manage their family? } \\
\hline Yes & 321 & 38.2 \\
\hline No & 519 & 61.8 \\
\hline \multicolumn{3}{|c|}{ Do you shake hands of epileptics? } \\
\hline Yes & 387 & 46.1 \\
\hline No & 453 & 53.9 \\
\hline \multicolumn{3}{|c|}{ Do you keep your child from contacting epileptics? } \\
\hline Yes & 336 & 40 \\
\hline No & 504 & 60 \\
\hline \multicolumn{3}{|c|}{ Do you agree to recruit epileptics as servant? } \\
\hline Yes & 210 & 25 \\
\hline No & 630 & 75 \\
\hline \multicolumn{3}{|c|}{ Do you agree your family member to marry epileptics? } \\
\hline Yes & 171 & 20.4 \\
\hline No & 669 & 79.6 \\
\hline \multicolumn{3}{|c|}{ Is Epilepsy treatable disease? } \\
\hline Yes & 258 & 30.7 \\
\hline No & 582 & 69.3 \\
\hline \multicolumn{3}{|c|}{ Do you think epileptics should not learn in schools? } \\
\hline Yes & 314 & 37.4 \\
\hline
\end{tabular}

DOI: http://dx.doi.org/10.4314/ejhs.v27i1.7 


\begin{tabular}{ccc}
\hline No & 526 & 62.6 \\
Do you think epileptics can lead healthy life style? & 367 & 43.7 \\
Yes & 473 & 56.3 \\
No & \\
\hline
\end{tabular}

Attitude towards epilepsy among study participants: More than one-thirds of the study participants (321(38.2\%), 330(39.3\%) and $303(36.1 \%)$ ) reported that they did not agree to work with epileptics, to have close relation and to live together with them respectively. Among the respondents, 252(30\%) think that epileptics should be isolated from the community. Less than two-thirds $(61.8 \%)$ of the participants did not think that epileptics can manage family. Among the study participants, 387(46.1\%) and $336(40 \%)$ did not want to shake hands with epileptics and keep their children away from epileptic patients respectively. Three-fourths (75\%) and nearly four-fifths $(79.6 \%)$ of study participants did not agree to recruit epileptics as servant and to arrange marriage of family members with epileptics respectively (Table 3 ). In this study, only $13.2 \%$ had positive attitude and the remaining $86.8 \%$ had negative attitude towards to epilepsy.

The FGD participants discussed on attitude of the community towards epilepsy. They noted that there was a high level of negative attitude. A 44 years old male uttered:

"Members of this community consider epileptic patients as insane; nobody will approach and eat or drink with epileptic patients. They do not marry them. In case if they unknowingly marry epileptic patient, they immediately decide to divorce."

Treatment Practice of study participants for epilepsy: Among the study participants, $89(10.6 \%)$ reported that epilepsy is treatable by traditional medicine, and 45(5.4\%) reported that traditional medicine is the only option for the treatment of epilepsy. Among the respondents $27.4 \%, 39.4 \%$, and $37.3 \%$ respectively reported that epilepsy is treatable by holy water, prayer and using matches. Among the study participants, more than half $(53.7 \%)$ said that they did nothing when they see epileptic patients on seizure. Less than one-thirds (28.8\%) reported that they protect patients from injury (Table 4).

The FGD participants explained the practice of the community during seizure episodes, and one of the male FGD participants noted:

'We help patients through slowly making them lie down on bed or ground and putting small pillow under head and if there is metallic materials, taking them away, inserting small woods/metal to avoid tongue biting, and sometimes, smoking match stick'".

Another participant from the female group said: 'Emm... Some people are getting well for three to ten years after praying. Look my wife stayed for ten years after good praying; no falling happened".

Table 4: Treatment practice of study participants towards epilepsy, Menit, 2015

\begin{tabular}{lll}
\hline Variables & Frequency & Percentage \\
\hline Is epilepsy treatable by traditional medicine & & \\
Yes & 89 & 10.6 \\
No & 751 & 89.4 \\
Is traditional medicine the only option? & 45 & 5.4 \\
Yes & 795 & 94.6 \\
No & & \\
Should epileptics take medicine for life long? & 657 & 78.2 \\
Yes & 183 & 21.8 \\
No & & \\
Is epilepsy treatable by holy water? & 230 & 27.4 \\
Yes & 610 & 72.6 \\
No & & \\
\hline
\end{tabular}

DOI: http://dx.doi.org/10.4314/ejhs.v27i1.7 
Is epilepsy treatable by praying?

Yes

No

Is epilepsy treatable by using match?

Yes

No

What do you do when you find epileptics on seizure?

Nothing

Keep patient

Give traditional medicine

Give holy water

Apply cold water others

What do people do when they find epileptics on seizure?

I don't know

Sacrifice for the sprit

Pray

Factors associated with knowledge and attitude: In multivariate analysis, the odds of being knowledgeable was lower among Bench and Menit ethnic groups compared with others. The odds of being knowledgeable was higher among those whose educational status was primary level and above compared with those who were unable
331

509

313

527

451

242

15

36

15

81

$\begin{array}{ll}430 & 51.2 \\ 62 & 7.4 \\ 348 & 41.4\end{array}$

to read and write (Table 5). The odds of having positive attitude were lower among Menit ethnic groups compared with others. The odds of having positive attitude was higher among those whose educational status was primary level and above compared with those who were unable to read and write (Table 6).

Table 5: Factors associated with knowledge towards to epilepsy Menit, 2015

\begin{tabular}{lll}
\hline Variables & Crude & Adjusted* \\
\cline { 2 - 3 } & OR $(95 \%$ CI $)$ & OR $(95 \%$ CI $)$ \\
\hline Age group(years) & 1.00 & 1.00 \\
$<20$ & $0.70(0.34,1.44)$ & $1.18(0.52,2.68)$ \\
$21-25$ & $1.01(0.51,2.03)$ & $1.66(0.71,3.87)$ \\
$26-30$ & $0.81(0.38,1.71)$ & $1.36(0.55,3.38)$ \\
$31-35$ & $0.61(0.29,1.32)$ & $1.01(0.41,2.52)$ \\
$>36$ & & \\
Income & 1.00 & 1.00 \\
$<500$ & $1.30(0.84,2.02)$ & $1.16(0.68,1.97)$ \\
501-1000 & $1.20(0.65,2.24)$ & $0.55(0.25,1.22)$ \\
$>1001$ & & \\
Distance from home to health facility (minutes) & $2.98(1.26,7.07)$ & $2.49(0.97,6.42)$ \\
$<30$ & $1.66(0.68,4.09)$ & $1.37(0.52,3.66)$ \\
31-60 & & 1.00 \\
$>60$ & 1.00 & 1.00 \\
Religion & 1.00 & $2.06(0.86,4.96)$ \\
Orthodox & $0.42(0.27,0.66)$ & $2.50(0.64,9.74)$ \\
Protestant & $0.89(0.33,2.38)$ & 1.00 \\
Others & & $1.31(0.74,2.30)$ \\
Married & 1.00 & $0.63(0.24,1.68)$ \\
Single & $1.06(0.67,1.69)$ & \\
Others & $1.25(0.59,2.66)$ & \\
\hline
\end{tabular}

DOI: http://dx.doi.org/10.4314/ejhs.v27i1.7 


\begin{tabular}{cll}
\hline Ethnicity & $0.21(0.11,0.39)$ & $0.20(0.08,0.51)$ \\
Bench & $0.20(0.12,0.31)$ & $0.14(0.06,0.35)$ \\
Menit & 1.00 & 1.00 \\
Others & 1.00 & 1.00 \\
Educational status & $1.78(1.03,3.10)$ & $1.40(0.75,2.63)$ \\
Do not read and write & $.97(3.17,7.80)$ & $3.64(2.11,6.28)$ \\
Able to read and read & & \\
Others & & \\
\end{tabular}

Table 6: Factors associated with attitude towards to epilepsy Menit, 2015.

\begin{tabular}{|c|c|c|}
\hline \multirow[t]{2}{*}{ Variables } & Crude & Adjusted* \\
\hline & OR $(95 \%$ CI $)$ & OR $(95 \%$ CI $)$ \\
\hline \multicolumn{3}{|l|}{ Age group(years) } \\
\hline$<20$ & 1.00 & 1.00 \\
\hline $21-25$ & $0.65(0.30,1.42)$ & $1.15(0.46,2.84)$ \\
\hline $26-30$ & $1.20(0.57,2.49)$ & $2.06(0.83,5.09)$ \\
\hline $31-35$ & $0.93(0.43,2.05)$ & $1.66(0.63,4.38)$ \\
\hline$>36$ & $0.75(0.34,1.66)$ & $1.24(0.47,3.27)$ \\
\hline \multicolumn{3}{|l|}{ Income } \\
\hline$<500$ & $1.37(0.86,2.17)$ & 1.00 \\
\hline $501-1000$ & $1.53(0.83,2.83)$ & $1.31(0.77,2.22)$ \\
\hline$>1001$ & 1.00 & $1.01(049,2.07)$ \\
\hline \multicolumn{3}{|c|}{ Distance from home to health facility (minutes) } \\
\hline$<30$ & $2.07(0.92,4.69)$ & $1.82(0.74,4.45)$ \\
\hline $31-60$ & $1.45(0.62,3.39)$ & $1.28(0.50,3.27)$ \\
\hline$>60$ & 1.00 & 1.00 \\
\hline \multicolumn{3}{|l|}{ Religion } \\
\hline Orthodox & 1.00 & 1.00 \\
\hline Protestant & $0.50(0.32,0.80)$ & $1.21(0.55,2.69)$ \\
\hline Others & $0.48(0.13,1.68)$ & $0.49(0.09,2.57)$ \\
\hline \multicolumn{3}{|l|}{ Marital status } \\
\hline Married & 1.00 & 1.00 \\
\hline Single & $0.90(0.55,1.47)$ & $1.17(0.66,2.09)$ \\
\hline Others & $1.15(0.52,2.53)$ & $0.75(0.28,1.98)$ \\
\hline \multicolumn{3}{|l|}{ Ethnicity } \\
\hline Bench & $0.35(0.19,0.65)$ & $0.48(0.20,1.15)$ \\
\hline Menit & $0.30(0.19,0.49)$ & $0.35(0.15,0.84)$ \\
\hline Others & 1.00 & 1.00 \\
\hline \multicolumn{3}{|l|}{ Educational status } \\
\hline Do not read and write & 1.00 & 1.00 \\
\hline Able to read and read & $1.25(0.68,2.30)$ & $1.03(0.53,2.01)$ \\
\hline Others & $3.99(2.52,6.31)$ & $2.96(1.71,5.14)$ \\
\hline
\end{tabular}

\section{DISCUSSION}

In this study, $97.1 \%$ of the study participants ever heard about epilepsy. This was much higher than the study conducted in King Abdulaziz
University Hospital, Saudi Arabia (70\%), and the study conducted in Tehran, Iran (76.6\%) $(15,16)$. This may indicate the high magnitude of the problem in our study area. 
The result of this study was comparable with that of a study conducted in Limpopo Province of South Africa and another study done among teachers in urban areas in North East of Brazil (90\% and 98\% respectively) $(17,18)$. However, these studies were conducted among educated groups.

In this study, $89(10.6 \%)$ of the participants reported that epilepsy is treatable by traditional medicine. This was lower than the study conducted in Saudi Arabia which was 59\%, but the latter included all non-medical treatments (15). This difference could probably be because the majority of the participants of this study $(69.3 \%)$ believed that epilepsy is not treatable or curable and the study was conducted on indigenous people.

The majority $(85 \%)$ of the study participants believed that epilepsy is a mental disease. This was higher than the findings of studies conducted in Saudi Arabia (48\%), London $(51.8 \%)$ and $\operatorname{Iran}(16.9 \%)(15,16,19)$. This difference could be due to cultural discrepancies.

The majority of our study participants $(69.3 \%)$ believed that epilepsy is not treatable or curable. This result was much higher than the study of Saudi Arabia(9\%) and India among second year college students (21\%) (20). Lack of education among our study participants might have contributed to this difference.

In this study, $49 \%$ of the participants believed that epilepsy is a contagious disease. This finding was much higher than the study conducted in King Abdulaziz University Hospital, Saudi Arabia (2\%), LPDR (Lao People's Democratic Republic) (33.3\%) and urban areas of Northeast Brazil $(2 \%)(18,21)$. This difference might be due to low literacy in our study area.

The result showing that $40 \%$ of the study participants keep their babies away from epileptic patients was much higher than the study conducted among dentists in London, Ontario which was $1.5 \%$ (19). This difference could probably be due to difference in study population as the former was conducted among the community whereas the latter was done among dentists who had better education. The other probable difference could be that, in this study, $49 \%$ of participants believed that epilepsy is a contagious disease. However, the result of our study was comparable with the study conducted in LPDR which was $39.1 \%$ (21).

In this study, $79.6 \%$ did not agree to allow family members to marry someone who is epileptic. This result was much higher than the study conducted among dentists in London, Ontario which was $5.2 \%$ (19). This could be because our study participants believed that this disease is contagious and hereditary. Yet, our result was comparable with the study conducted in LPDR which indicated that $27.8 \%$ of the study participants would allow their children to marry epileptic patients (21).

The result which indicated that $40.6 \%$ of the respondents believed that epilepsy is hereditary was higher compared with the study conducted in Limpopo Province of South Africa, the study conducted among medical outpatients in Lahore, Pakistan and the study conducted in Northern Nigerian community which were $4.9 \%$ and $8.8 \%, 19.1 \%$ respectively $(17,22,23)$. Differences in culture and literacy may contribute to this disparity. However, the result of our study was lower than the study conducted in Tehran, Iran, which was $47.1 \%$ (16).

This study showed that the prevalence of not wanting to shake hands with epileptic patients was $53.9 \%$. This was comparable with the study conducted in Limpopo Province of South Africa (50.8\%) (17).

About $43.7 \%$ reported that epileptic patients can lead a healthy life. This result was lower compared with the study conducted in LPDR which indicated that $78.2 \%$ respondents reported that epileptic patients can have normal life after treatment (21). This difference could be due to differences in source populations. The latter was conducted among health workers whereas our study was conducted on a community with low literacy.

In our study, $8.5 \%$ of the study participants had family member who were epileptic. This was lower compared with the study conducted in Tehran, Iran, which was $23.9 \%$ (16). However, the latter included relatives in addition to family members.

In this study, the level of knowledge and positive attitude were $14.4 \%$ and $13.2 \%$ 
respectively. This result was very low compared with the study conducted among teachers in Fars Province of Iran which revealed that $40 \%$ individuals had knowledge and more than twothirds had positive attitude towards epilepsy (24). This difference could be due to difference of educational status of the study participants. The low level of knowledge and attitude in this study was also supported by the qualitative study. The FGD participants believed that epilepsy is God's curse and associated evil spirit. In addition, ethnicity and educational status were significantly associated with knowledge and attitude. This could be due to cultural belief in the ethnic group specially Menit Community and low access to education among the ethnic group. This was supported by a case report conducted in the same community (25).

In conclusion, the level of knowledge about epilepsy was low, and the attitude towards the disease was not appropriate. Ethnicity and educational status were significantly associated with knowledge and attitude. The local government should work to create awareness on and change negative attitude towards epilepsy. Local media need to plan to provide education.

\section{ACKNOWLEDGEMENTS}

We would like to express our great thanks to Mizan-Tepi University for funding this research work. We also thank all study participants who were involved in this research.

\section{REFERENCES}

1. Mulat G, etal. Knowledge, attitude and practices with respect to epilepsy among preparatory school students in Mekele city, Ethiopia. Internal journal of collaborative research on internal medicine and public health 2012;4(3):203-215

2. International League against Epilepsy. Quality of life: General considerations. Epilepsia 2003;44(6):57-58.

3. Harde $\mathrm{C}$, etal.The effect of seizure severity on quality of life in epilepsy. Epilepsy Behavior 2007;11(2):208-11
4. Yemadje L, etal. Understanding the differences in prevalence of epilepsy in tropical regions. Epilepsia 2011; 52: 1376-1

5. Leonardi $\mathrm{M}$, etal. The global burden of epilepsy. Epilepsia 2002;43(Suppl. 6):21-5.

6. Pahl K, etal. Epilepsy and rights. In: Atlas: epilepsy care in the world. Geneva: WHO; 2005. p. 72-3.

7. Hekele M. The global burdens and stigima of epilepsy. Epilepsy and Behavior 2008; 12:540-546

8. Sander J. The epidemiology of epilepsy revisited. CurrOpinNeurol 2003; 16:165-70.

9. Duncan J, etal. Adult epilepsy.Lancet 2006;367:1087-100.

10. Wiebe S, etal. Burden of epilepsy: the Ontario Health Survey. Can J NeurolSci 1999;26:263-70.

11. Aldenkamp A, etal. Newer antiepileptic drugs and cognitive issues. Epilepsia. 2003;44(suppl 4):21-29.

12. World Health organization: Epilepsy in the WHO south-east Asian region.Bridging the Gap; the global complain against the epilepsy "out of the shadows",2005

13. International league against epilepsy the history and stigma of epilepsy; Epilepsia2003; 44(suppl.6)12-14,.

14. Westphal G, etal.Quality of life and burden in caregivers of patients with epilepsy.JNeurosciNurs. 2007; Dec;39(6):354-60.

15. Zainy. Parents' knowledge and attitudes toward children with epilepsy. Neurosciences 2013; Vol. 18 (4)345-48

16. Helia G, et al. Public awareness and attitudes towards epilepsy in Tehran, IranGlob Health Action 2013; 6: 216-18 Available from: http://dx.doi.org/10.3402/gha.v6i0.21618

17. Mangena N. Perceptions about Epilepsy in the Limpopo Province of the Republic of South Africa. Curationis 2003; 51-56

18. Fabio G, etal. Knowledge and attitudes toward epilepsy among primary, secondary and tertiary level teachers. Arq Neuropsi quiatr 2001; 59(3-B): 712-16

19. Cecilia E. Knowledge and Attitudes about Epilepsy: A Survey of Dentists in London, Ontario.JCDA2009; Vol. 75, No. 6 450-459. 
Available from: www.cda-adc.ca/jcda/vol75/issue 6/450.html

20. Sudarshan S, etal.Knowledge of epilepsy among IInd year students of medical fraternity. International Journal of Advances in Scientific Research, 2015; 1(04): 186-190

21. Harimanana et al. Is insufficient knowledge of epilepsy the reason for low levels of healthcare in the Lao PDR?. BMC Health Services Research, 2013; 13:41. doi:10.1186/1472-6963-13-41.

22. Naeem F, etal. () 'A survey of knowledge and attitude of the general public towards epilepsy in Lahore, Pakistan.'Journal of
Pakistan Psychiatric Society, 2007; 4(2): 9699.

23. Kabir M, etal. Knowledge, attitude and beliefs about epilepsy among adults in a northern nigerian urban community. Annals of african medicine2005; vol. 4, no. 3: 107 112

24. Asadi-Pooya A, etal. Knowledge and Attitude towards to Epilepsy among Biology Teachers in Fars Province, Iran. Iranian journal of child neurology, 2012;6(1):13-18.

25. Henok A, etal. Unbelievable Beliefs behind Epilepsy: A Case Report from South West Ethiopia. J Community Med Health 2015; 5:374. doi: 10.4172/2161-0711.1000374 